\title{
A INFLUÊNCIA DAS REDES SOCIAIS NO MARKETING POLÍTICO PARA AS CADIDATURAS POLÍTICAS DO BRASIL
}

\section{THE INFLUENCE OF SOCIAL NETWORKS IN POLITICAL MARKETING FOR THE POLITICAL CADIDATURAS OF BRAZIL}

\author{
José Raimundo Gomes de Oliveira Júnior \\ Graduando em Administração - Alfa Unipac - Brasil \\ E-mail: raimundo142@gmail.com
}

Edvaldo Silva Dutra

Especialista, Alfa Unipac - Brasil

E-mail: prof.eddutra@hotmail.com

Recebido: 20/11/2020 - Aceito: 27/11/2020

\section{Resumo}

A utilização do marketing digital pode ser determinante no processo de crescimento nas candidaturas políticas, visto o alcance tecnológico das mídias sociais nos quatro cantos do Brasil. Há 20 anos, era inimaginável a possibilidade de uma tecnologia que alcançasse em tempo real, um número tão expressivo de pessoas, o que traz à tona o tino de utilização dessa ferramenta para se tratar da política, não apenas nas campanhas, mas como instrumento de participação e debate. Nesse sentido, o artigo em tela se propõe analisar a importância da utilização das ferramentas do marketing político digital na realidade das cidades do Brasil, abordando seu alcance e efetividade no processo de campanha dos candidatos que pleiteiam as eleições municipais. Assim, o trabalho se propôs a realizar um estudo a partir de uma revisão de literatura, abordando as possibilidades tecnológicas do marketing digital, ampliado por sua capacidade de aproximar os candidatos dos eleitores, orientar e direcionar as ideias, bem como coletar as sugestões da população. Nesse percurso, foi possível analisar o tema e revisar conceitos e sua aplicabilidade na realidade do povo brasileiro, levando-se em consideração as estratégias e as ferramentas do Marketing Político Digital, pré e pós período eleitoral. Para o levantamento bibliográfico, foram realizadas pesquisas em livros, revistas e artigos científicos, bem como material eletrônico de sites como SCIELO e LILACS, buscando primar pela qualidade e confiabilidade do material pesquisado. Para tanto, o artigo científico que aqui se configura foi dividido em quatro partes, além da Introdução.

Palavras-chave: Marketing Político; Marketing Digital; Internet.

\section{Abstract}

The use of digital marketing can be decisive in the process of growth in political applications, given the technological reach of social media in Brazil. Twenty years ago, it was unimaginable the possibility of a technology that would reach in real time, such an expressive number of people, 
which brings to light the time of using this tool to deal with politics, not only in campaigns, but as an instrument of participation and debate. In this sense, the article proposes to analyze the importance of using digital political marketing tools in the reality of Brazil cities, addressing theirs cope an defectiveness in the campaign process of candidates who call for municipal elections. Thus, the work aimed to conduct a study based on a literature review, addressing the technological possibilities of digital marketing, expanded by its ability to bring candidates closer to voters, guide and direct ideas, as well as collect the suggestions of the population. In this journey, it was possible to analyze the them and review concept sand their applicability in the reality of the Brazil ian people, taking into accountth strategies and tools of Digital Political Marketing, before and after the election period. For the bibliography icsurvey, research was carried out in books, journal sands cientific articles, as well as electronic material from sites such as SCIELO and LILACS, seeking to excel at the quality and reliability of the researched material. To this end, the scientific article that is configured here was divided into four parts, in addition to the Introduction.

Keywords: Political Marketing; Digital Marketing; Internet.

\section{Introdução}

A Internet integra uma área da tecnologia da informação de alcance mundial, cada dia mais abrangente e de repercussão imediata, inovando de forma a possibilitar novas maneiras de interação conectada, em uma rede global. Com esse avanço adentrando todas as áreas de conhecimento, propaganda, venda, informação e as infindáveis possibilidades de utilização, o campo político encontra nessa seara, a oportunidade de alcance de um público, que nos modos tradicionais e em curto espaço de tempo, dificilmente seria alcançado.

O uso da tecnologia digital pela política, bem como das redes sociais possibilitou grandes avanços na atuação política para além dos canais institucionais. O marketing político adentra a agenda nacional como uma ferramenta extremamente importante na progressão da comunicação, atrelando a aproximação e o debate com o eleitor. O marketing político digital tem ganhado espaço exponencial no campo das campanhas desde o início dos anos 2000, sendo a internet cada vez mais utilizada como instrumento dos candidatos, potencializada pela popularização da internet nos últimos anos.

Nesse sentido, o marketing político é entendido em sua utilização, como uma analogia do marketing na atividade política. Tal atividade tem se adaptado às novas possibilidades que a tecnologia digital estabelece, ampliando a cobertura da comunicação em massa e em tempo real, potencializada pelo aumento no número de usuários pelo mundo afora. 
O número de pessoas com acesso a internet tem crescido de forma avassaladora. De acordo com a Organização das Nações Unidas - ONU, em estudo realizado em 2019, mais da metade da população mundial fazem uso da internet, ou seja, 4,1 bilhões de pessoas. Já em 2020, a plataforma internacional de estatísticas, Statista, revelou que cerca de 4,57 bilhões de pessoas fizeram uso da internet todos os dias do mês de abril do corrente ano, ressaltando que as redes sociais foram os aplicativos mais buscados no período. (ONU, 2019) (ECOMMERCEBRASIL, 2020)

$\mathrm{Na}$ realidade brasileira, 03 (três) a cada 04 (quatro) brasileiros acessam a internet, o que equivale a 134 milhões de pessoas. A pesquisa declara que pelo menos $74 \%$ dos brasileiros acessaram a internet pelo menos uma vez num período de 03 (três) meses. Na maioria dos casos, os acessos se deram por meio de smartphones. (VALENTE, 2020)

Nesse panorama, os meios de comunicação em rede se destacam como um espaço privilegiado para a política. No caso do marketing político digital, Penteado (2011) elabora que as características da internet permitem práticas colaborativas e interativas entre os usuários, possibilitando a ampliação da democracia e a maior participação da população no processo eleitoral. Assim, os candidatos as eleições utilizam-se das redes sociais como um canal de diálogo com os eleitores, alcançando cada vez mais espaços.

Nas eleições municipais de 2020, a utilização das redes sociais apresentase com força total no campo do marketing político, potencializada pela crise exercida pela pandemia da COVID-19, já que os canais online ganharam ainda mais expressividade no processo de comunicação no país.

Nesse contexto, o artigo em tela busca apontar uma breve análise acerca da influência das redes sociais para as candidaturas políticas no Brasil, sobretudo, nas cidades interioranas, abordando seu alcance e efetividade no processo de campanha dos candidatos que pleiteiam as eleições municipais.

\section{O marketing político no brasil}

\subsection{Marketing político}


O marketing político diz respeito a um conjunto de técnicas e procedimentos cujo objetivo é adequar um candidato a seu eleitorado em potencial, procurando fazer com que este fique cada vez mais conhecido e que se destaque dos outros candidatos de forma positiva.

Nesse contexto, o marketing político é definido como a "arte de informar e comunicar com o eleitor; orientar e direcionar as ideias do partido, candidato ou governo, em função das necessidades identificadas, é definir o seu público e satisfazê-los". (SILVA e FERREIRA JÚNIOER, 2013, p. 3)

Para Dantas (2010 apud PIMENTA e FERREIRA, 2017), o marketing político apresenta-se como a criação e promoção da imagem de um candidato durante a sua carreira pública e está ligado a preocupação do candidato com a concordância entre sua plataforma política e os anseios do eleitorado.

Por outra banda, Oliveira (2015) aponta que no marketing político, são trabalhados os mesmos conceitos do marketing tradicional, atuando de forma a agregar valor a determinado produto perante o cliente. Nessa mesma ideia, Dantas (2000 apud PIMENTA e FERREIRA, 2017) já destacava que assim como o marketing tradicional, que é formado pelo conhecido 4Ps, referente ao produto, preço, praça e promoção, o marketing político, também apresenta 4 letras, todavia, diz respeito ao político, ao voto, a comunicação e a distribuição.

Nessa vertente, o marketing político

consiste em práticas que primeiramente definem as necessidades da população em geral, com a realização de pesquisas, seguindo com planejamento que se refere a propriedades do produto (candidato), preço (valor percebido pelos eleitores, que se materializa no voto), promoção e distribuição, seguindo com a comercialização do produto, explanação da plataforma política do candidato ao seu público-alvo, finalizando com a gerência de produção, ou seja, a gestão da imagem do candidato junto ao seu eleitorado. (DANTAS, 2009 apud PIMENTA e FERREIRA, 2017, p. 5)

É fundamental para a atividade profissional de marketing político, o direcionamento da campanha, o alinhamento da imagem e da mensagem em que 
deverão ser divulgadas na campanha, visto que as ações de marketing político são orientadas e adaptadas às necessidades dos eleitores de cada região. (QUEIROZ, 2006 apud OLIVEIRA, 2015).

Convém salientar que no marketing político, o candidato deve ter atributos positivos, com programas que agregam valor ao eleitorado, além de ser verdadeiro, comprometido e ético.

\subsubsection{Político}

No marketing político, o político é entendido como o produto, todavia, o político é algo inatingível no que diz respeito aos resultados, já que suas propostas, ou seja, seu produto, só poderá ser consumido ao longo de quatro anos.

Importa considerar que um candidato engloba uma série de peculiaridades, próprias e individuais, enquanto ser humano e, sem deturpar seus traços de personalidade, deve moldar seu perfil político em detrimento das necessidades do eleitor.

Para inserção no meio político, o candidato deve estar filiado em algum partido político, já que no Brasil, nenhum candidato pode lançar sua candidatura sem filiação partidária. Para Dantas (2010 apud PIMENTA e FERREIRA, 2017), o partido é para o candidato o que a empresa significa para o produto, ou seja, não existe produto sem empresa, nem candidato sem partido. Por conta disso, a importância de escolher um partido ao qual mais se identifica com o perfil do candidato.

A decisão de qual partido se filiar, já diz muito sobre o perfil do candidato, podendo se aproximar ou se afastar do eleitorado, dependendo da realidade política da região. Daí surge a importância de uma campanha política bem elaborada e mais próxima possível da população. Como o político não tem como ter verificada sua qualidade antes para assegurar o valor do voto, a conquista da confiança pelo eleitores é fundamental.

O político é um produto que pensa, fala e tem ação própria, e que se bem trabalhado, com autenticidade, pode gerar uma sensação de confiança para com os eleitores, ao passo que a desconfiança pode ser atiçada nos casos em que o 
candidato apresenta conduta incoerente com o discurso, ou seja, o candidato tenta camuflar sua imagem em prol da aprovação do eleitor.

Nesse sentido, no marketing político, o produto diz respeito ao político, a plataforma do partido, aos registros de candidaturas anteriores e as características pessoais do candidato.

\subsubsection{Voto}

O voto é para o marketing político, o que o preço é para o marketing tradicional. Isso quer dizer que quando o eleitor vota em determinado candidato, ele está comprando a ideia que o candidato apresentou durante todo o período de campanha eleitoral. Seu voto então representa a confiança de que se eleito, o candidato realizará feitos aos quais foram prometidos em campanha.

Dantas (2010 apud PIMENTA e FERREIRA, 2017, p. 7) afirma que o "voto é o preço que o eleitor está disposto a pagar para adquirir os serviços que o político ofereceu durante a campanha".

Para Muniz (201-?) o voto é a consequência de um processo que se realiza ao passo que se deflagra a campanha. Por isso a importância do candidato se aproximar e ouvir as demandas dos eleitores, a fim de compatibilizar sua campanha com os anseios da população e potencializar as intenções de voto.

\subsubsection{Distribuição}

A distribuição trata-se da forma de como a imagem do candidato chega para os eleitores. Assim, possui variáveis diversas, compostas pelos meios de comunicação, tais como revistas, televisão, jornais, panfletos, mídias sociais, carros de som, corpo a corpo, etc.

No caso, o objetivo é fazer com que a imagem do candidato chegue no momento certo aos eleitores. Assim, fatores chave são observados pelos eleitores, como ligações políticas e apoiadores e, acessibilidade do político, identificada a 
partir de sua disposição em comparecer aos compromissos de campanha e atender os eleitores.

\subsubsection{Comunicação}

A comunicação no marketing político diz respeito a todos os tipos de comunicação realizadas pelos atores políticos para fins eleitorais. Esta se dá a partir de um emissor, que no caso é o político e sua equipe de campanha.

Hansen et al, (2001 apud SOUZA, 2009) registra que comunicações políticas são entendidas como sistemas, crenças e práticas envolvidas na construção, distribuição e recepção da informação política, construindo alianças, gerando conhecimento e criando significado.

Barbero conceitua comunicação política e marketing político como "um conjunto de teorias, métodos, técnicas e práticas sociais, inspiradas no marketing comercial que tem como principal objetivo promover imagens entre indivíduos, grupos, instituições, projetos e ideias políticas, num processo eleitoral, e aumentar a influência eleitoral e política". (BARBERO, 2006 apud SOUZA, 2009, p. 43)

No caso do marketing político, a comunicação deve ser efetiva, devendo surtir os efeitos desejados e necessários para o sucesso da candidatura. A publicidade eleitoral é muito utilizada.

Vale expor que a Internet potencializou a disseminação da comunicação em temo real, alcançando um público muito maior e diferenciado. Atrelado a outros meios de comunicação, a candidatura política apresenta uma dimensão muito mais abrangente.

\subsection{Marketing Político nas redes sociais}

A internet adentra o mundo da política de forma a fortalecer os espaços de comunicação entre candidatos e eleitores. A evolução da comunicação na internet atuou de maneira que o marketing político tradicional evoluísse para os meios eletrônicos, de forma que os usuários controlassem a quantidade, o tipo de informação e o momento que deseja receber tal informação. (OLIVEIRA, 2000 apud 
CARDOSO, et al, 2018) Nesse sentido, os consumidores das mídias digitais passaram a interagir nas redes, a conhecer, a questionar,comparar e a opinar.

Pimenta e Ferreira (2017) destacam que várias são as vertentes do marketing, dentre elas, o marketing político digital, cujo intuito é suprir as necessidades do eleitorado a partir da divulgação de um candidato ou um gestor público, utilizando-se de estratégias mercadológicas como as mídias sociais, a fim de disseminar instantaneamente as informações desejadas.

Além das redes sociais, outras plataformas eletrônicas podem ser exploradas para alavancar a campanha política, tais como sites, blogs, WhatApp, entre outros. Importa considerar que as mídias sociais funcionam como uma ferramenta a mais no processo de comunicação, mas não deve ser o único.

A ferramenta do marketing político digital sobrepõe a barreira da distância e do tempo, fazendo com que a comunicação chegue instantaneamente ao eleitor seja onde quer que ele esteja, potencializando a comunicação e a informação, aproximando o eleitor do candidato e proporcionando maior alcance de todos os candidatos ao nicho eleitoral. (SILVA e FERREIRA, 2013)

Gama elabora que a internet, traz consigo um acesso quase que irrestrito a todo e qualquer tipo de informação e, além disso, "cria aos políticos, a possibilidade de atingir vários públicos, ouvir os eleitores e levar suas propostas e críticas aos adversários, utilizando-a como uma excelente ferramenta de marketing pessoal". (GAMA, 2013, p.3)

Importa considerar que as mídias sociaistem ganhado força exponencial como ferramenta do marketing político na atualidade, transformando os moldes das campanhas eleitorais dos últimos anos. Tal instrumento tem favorecido a forma em que a informação chega ao público e o retorno gerado pelo feedback imediato, ou seja, informação e diálogo andam juntos.

Nesse contexto, Carlson e Djupsund contemplam as vantagens da internet para o marketing político, quando apontam que

o comunicador tem pleno controle sobre a mensagem. Normalmente ele não é censurado ou filtrado por outros, isto é, a mensagem que é enviada ao destinatário supera o processo de edição jornalística. Segundo, a internet é potencialmente interativa, isto é, torna-se possível um diálogo de 
mão dupla entre quem envia e quem recebe. Terceiro, o novo meio provê àquele que envia um recurso relativamente barato para transmitir grandes volumes de informação. Finalmente, a técnica sofisticada da comunicação via Web dá ao consumidor uma ampla gama de possibilidades donde escolher a forma de comunicação (texto, imagens, som e vídeo) considerada mais apropriada para uma mensagem particular. Em conclusão, a Web provê aos agentes políticos com a oportunidade pela qual ansiava, isto é, a de ter controle total sobre a produção da mensagem e comunicar diretamente com os potenciais eleitores sem ter os meios de massa filtrando-se a informação. (CARLSON e DJUPSUND, 2001, p. 69 apud GAMA, 2013, p.3)

Ao que pode ser observado, as mídias sociais reduzem sobremaneira a necessidade de mediadores da informação, fazendo com que o conteúdo chegue ao seu destino exatamente como desejado.

No contexto atual do marketing político, as mídias sociais encontram-se como fatores decisivos aos milhares de brasileiros que utilizam da internet e que são influenciados pelo meio eletrônico na hora do voto. Por isso, a importância de estratégias e planejamento dos candidatos, que devem sobretudo, primar pela qualidade e veracidade da mensagem transmitida. Para tanto, os candidatos deverão se cercar de gente competente para operar essas tecnologias.

Importa registrar que cada rede social apresenta um objetivo e alcance específico, devendo o candidato fazer o melhor uso daquilo que the é disponibilizado. A Mídia Social trata-se de um termo mais abrangente, que inclui todas as ferramentas e canais da Internet utilizados para compartilhar informações, ao passo que as Redes Sociais são mais focadas no relacionamento entre as pessoas.

Como principais mídias sociais na atualidade, vale destacar:

-YouTube: considerada a rede social mais utilizada pelos brasileiros, já que cerca de $95 \%$ dos internautas brasileiros fazem uso da plataforma. De acordo com o relatório Digital In 2019, o YouTube é a principal rede social de vídeos online da atualidade, com mais de 1 bilhão de usuários ativos e mais de 1 bilhão de horas de vídeos visualizados diariamente. 
- Facebook: alcança a segunda posição das redes sociais mais utilizadas entre os brasileiros e a mais utilizada pela população mundial, com mais de 2,2 bilhões de contas ativas. No Brasil, o número de contas ativas chegam a 130 milhões. O Facebook reúne muitas funcionalidades e serve tanto para gerar negócios quanto para conhecer pessoas, além de ser uma plataforma interessante para se relacionar com amigos e familiares, bem como se informar.

- WhatsApp: caracteriza-se como a rede social de mensagens instantâneas mais popular entre os brasileiros, já que praticamente todas as pessoas que possuem um smartphone fazem uso desse aplicativo. De acordo com a pesquisa da Digital In 2019, 89\% dos internautas fazem uso do WhatsApp.

- Instagram: caracteriza como uma das mídias sociais que mais cresceu nos últimos anos. É utilizada tanto para relacionamentos quanto para gerar negócios. Possui a ferramenta do Status e IGTV. Segundo o Sprout Social (2019), são mais de 1 bilhão de usuários ativos no mundo.

- Facebook Messenger: é a ferramenta de mensagens instantâneas do facebook.

- Twitter: considerado o microblog mais famoso da internet, caracteriza-se por aceitar apenas pequenos textos, de até 140 caracteres.

- Linkedln: consolidada a maior rede social de negócios do mundo. Tem foco na geração de conexões e relacionamento. No Linkedln, os profissionais podem criar seu currículo, buscar empregos e fazer contatos com pessoas do mundo inteiro.

- Pinterest: funciona como um catálogo de ideias e tem um público majoritariamente feminino. Caracteriza-se por uma rede social que permite descobrir, compartilhar e salvar ideias. Também amplamente utilizada para negócios.

- Snapchat:rede social voltada para o compartilhamento de fotos e vídeos que podem ser visualizados pelo tempo de duração de 24 horas. É bastante utilizada entre os jovens.

Para Gehm (2012 apud MOLINA, 2019), um dos critérios para a construção da presença no marketing digital é a propagação da informação, com o objetivo que os usuários das redes se sintam provocados a compartilhar as postagens. 
Há de se registrar que as mídias sociais para os políticos é uma realidade que adentra o cenário eleitoral brasileiro de forma avassaladora, e os políticos precisam se enquadrar nessa nova demanda. Importante se faz ater-se em que tipo de relação será construída com os eleitores. Deve-se aproximar ao máximo dos cidadãos, e para isso, é necessário interação e linguagem apropriada, com conteúdo esclarecedor e propostas que façam sentido para a população.

\subsection{O Marketing Político Digital nas campanhas eleitorais brasileiras}

A globalização e o avanço da tecnologia traz consigo para os quatro cantos do mundo uma realidade a qual engole os moldes tradicionais de fazer política, exigindo cada vez mais uma postura diferenciada dos candidatos, muito além dos tapinhas no ombro, das compras de voto e das promessas infundadas de campanha.

Com o advento da internet, potencializado por sua popularização, os eleitores passaram de agentes passivos e submissos, a ativos pensantes, questionadores e participantes de todo o processo pré e pós eleição. A atuação política do candidato passa instantaneamente pelo crivo do eleitor, que adentra o universo da candidatura e age como uma espécie de termômetro, sinalizando se o candidato vai bem ou não.

Grosselli registra que os usuários da internet precisam constantemente buscar informações sobre as últimas tendências cibernéticas e notícias atuais sobre partidos políticos e candidatos, avaliando se estes se encontram de uma forma ou outra, ultrapassados. (GROSSELLI, 2010, p. 94)

O administrador de empresas e professor da Academia do Marketing do Rio de Janeiro, Alberto Valle, elabora cinco dicas para o marketing político digital, conforme a seguir.

1 - Apresente-se como uma pessoa e não como um candidato, pois nas redes sociais as pessoas querem contatos com outras pessoas e não com um personagem. Deixe para anunciar a sua candidatura depois de ter construído laços, afinal marketing nas mídias sociais é um trabalho de construção de laços de relacionamento. 
2 - Mostre as suas qualidades como gestor, líder ou representante social e não parta para o ataque puro e simples de seus adversários. O eleitor está cansado desse tipo de discursos de ódio que tenta convencê-lo de que e melhor votar em um determinado candidato, porque o outro é pior.

3 - Ofereça algo antes de pedir votos. O marketing de conteúdo será o grande destaque nas redes sociais para as eleições de 2018, portanto, agregue valor ao dia a dia das pessoas, ao invés de ficar simplesmente pedindo votos. Deixe isso para a etapa final de campanha e não para a largada.

4 - Busque pessoal capacitado para trabalhar em sua campanha. Marketing nas redes sociais é coisa séria e cada vez mais técnica. Não dá para confiar a sua campanha àquele "sobrinho esforçado que mexe com computador". No marketing digital de hoje em dia, não há espaço para amadorismo ou improvisos.

5 - Prepare-se para investir em sua campanha on-line. Não há nada de graça na Internet e ne nas redes sociais. Se você quiser uma boa exposição em canais como o Facebook, Instagram e Twitter, prepare-se para investir pesado em impulsionamento, pois o alcance orgânico, aquele que você consegue sem pagar nada, não passa de $2 \%$ do seu público. (BELMONTE, 2018, p.3)

Isso quer dizer que a qualificação dos candidatos é cada vez mais, elemento de avaliação por parte do eleitorado, e sua inadequação, faz com que este seja automaticamente jogado a escanteio.

Um dos pontos de maior observância por parte do eleitorado é avaliar se o candidato realmente conhece a realidade local e as principais demandas da população. Assim, Cabrinoesclarece que é preciso estabelecer estratégias para que a relação candidato/eleitor seja potencializada, devendo ter em mente etapas importantes para o início das atividades de campanha. A primeira etapa diz respeito à pesquisa de mercado, a segunda diz respeito ao diagnóstico, a terceira sobre o planejamento das estratégias, a quarta ao conceito do candidato e a quinta sobre a 
estratégia de comunicação, devendo todas serem complementares. (CABRINO, 2002 apud PIMENTA e FERREIRA, 2017)

Braga e Carlomagno (2018) apontam que as últimas campanhas eleitorais brasileiras se caracterizaram pelo uso maciço da internet e das mídias sociais como ferramenta de propaganda política, marcando a forte e crescente tendência de utilização cada vez mais expressiva dos meios virtuais nas campanhas políticas.

\section{AS REDES SOCIAIS E SUA INFLUÊNCIA NA POLÍTICA}

\subsection{Evolução histórica do uso da Internet nas campanhas políticas brasileiras}

As campanhas eleitorais voltadas em larga escala para as mídias digitais ganham força no Brasil, a partir do exemplo da campanha de Barack Obama para presidente do Estados Unidos em 2008. Tendo em vista a notoriedade gerada durante a campanha, outros políticos passaram a utilizar esses espaços nas campanhas subsequentes em diversas partes do mundo.

O ano de 1998 lançou-se como o ano que deu início às primeiras experiências de utilização da internet e das tecnologias digitais no Brasil. Em meados dos anos 2000 a inserção de novas tecnologias nas propagandas eleitorais foram experimentadas, como por exemplo, e-mails, websites, blogs e a rede social Orkut. Para os autores supramencionados, embora no Brasil, os níveis de inclusão digital ainda fossem reduzidos, a internet tornou-se um canal de comunicação que apresentou importantes possibilidades em termos de mobilização e engajamento dos eleitores mais envolvidos com a política. (COUTINHO e SAFATLE, 2009 apud BRAGA e CARLOMAGNO, 2018)

Em 2008, o avanço no uso da internet nas eleições municipais foi bastante comentado, gerando um impacto positivo no pleito daquele ano, entretanto, foi apenas em 2010 que as tecnologias digitais trouxeram maior grau de difusão entre os candidatos. Para Braga e Carlomagno, tal fator se deu em virtude de dois motivos básicos. O primeiro diz respeito àqueda das restrições dos tribunais eleitorais no amplo uso da internet pelos candidatos e, em segundo lugar, a 
influência da bem sucedida campanha presidencial de Barack Obama de 2008, que gerou grande euforia no campo do marketing político. (BRAGA e CARLOMAGNO, 2018)

Ainda que a internet tenha chegado ao Brasil nos anos 90, a expansão dessa tecnologia só se deu a partir do início do século XXI. Conforme dados do IBGE, a proporção de usuários da internet no Brasil passou de 20,9\% no ano de 2005 para 69,8\% em 2017. Em 2019, o número de usuários da rede no Brasiljá atingia um montante de 134 milhões de pessoas.(IBGE, 2019)

Registra-se que a expansão do uso das redes e mídias sociais para publicizar conteúdo político e de campanha, fez com que o Tribunal Superior Eleitoral - TSE, preocupado com a possibilidade da prática de abusos, estabelecesse limites para 0 uso da internet nas campanhas eleitorais brasileiras.Nesse sentido, em 2009, o Congresso Nacional editou a Lei no 12.034 de 29 de setembro de 2009, que passou a regulamentar o uso da internet em campanhas eleitorais. Tal Lei, conhecida como Minirreforma Eleitoral, assegurou a livre manifestação do pensamento durante a campanha eleitoral, bem como o direito de resposta no caso de divulgação de informações inverídicas.

$\mathrm{Na}$ época da campanha eleitoral brasileira de 2010, duas inovações tecnológicas foram amplamente utilizadas pelos candidatos, os Websites e o Twitter. Em contraponto, surgiram as primeiras fakenews. Cruz aponta que em 2010 já se observavam espaços de comunicação política que fugiam do controle das campanhas, "através da constituição de canais de debate espontâneo nos fóruns de internet”. (CRUZ, 2020, p. 14)

Nos pleitos de 2012 e 2014, o Facebook entrou com força total e se consolidou como o preferido na propagação das candidaturas políticas, tendo em vista o uso da internet para o ativismo e a militância política. Cruz ressalta que foramnas eleições de 2014 que as campanhas passaram a terum olhar a mais para a internet e as redes sociais, entretanto, nessa época, as mídias sociais ainda apresentavam-se como um complemento à campanha da televisão. (CRUZ, 2020)

Nesse mesmo ano, entrou em vigor a Lei no 12.965, conhecida como Marco Civil da Internet, cujo objetivo foi estabelecer princípios, garantias, direitos e 
deveres, ou seja, a lei regulamentou os parâmetros nacionais para o uso da internet.

Em 2016, a campanha política apresentou um maior grau de interatividade virtual com os eleitores, movida por variados formatos de mídias sociais. Mas foi em 2018 que as campanhas digitais se manifestaram de forma mais incisiva no Brasil, desestabilizando os padrões tradicionais de política cristalizado ao longo das décadas.

Francisco Brito Cruz, organizador do livro "Internet e Eleições no Brasil" reflete que

com a chegada do "fator internet", esses contornos se alteraram e, em uma era na qual "comunicação de massa" ("de um para muitos") e "autocomunicação de massa" ("de muitos para muitos") coexistem e interagem, novos atores e espaços passam a compor as campanhas políticas, em diversos tipos de relacionamento, dando vida a novos formatos de campanha que podem ser compreendidos como "estruturas de campanha em rede". (CRUZ, 2020, p. 15)

Em vistas do poder das mídias sociais, o Facebook, o Instagram, WhatsApp e outros meios de comunicação digital foram ampliando seus espaços quando muitos dos candidatos passaram a fazer uso dos mesmos como ferramentas de marketing político no Brasil.

Para Castro Pinto,

a internet é um espaço cibernético livre e democrático por excelência, além de constituir uma ferramenta tecnológica poderosíssima que pode dinamizar o processo eleitoral, visualizar a cidadania, angariar recursos para a campanha eleitoral, e levar os cidadãos, principalmente, os jovens a se interessar pela vida política. (CASTRO PINTO, 2010, apud GROSELLI, 2010, p. 97)

Nesse contexto, ao que tudo indica, o uso das mídias sociais veio para ficar no Brasil e no mundo, tornando-se ingrediente indispensável nas campanhas eleitorais. Para Satuf e Vasconcelos (2019), uma das maiores inovações que 
acompanham o mundo digital é a forma de como a informação é distribuída. Atualmente, qualquer pessoa, com conhecimento e recursos suficientes, pode produzir conteúdo, bem como participar de debates e discussões.

Conforme informações prestadas por COSTA (2018), a maior parte do país está presente no mundo digital, principalmente em redes sociais como o Facebook, o Instagram, YouTube e o WhatsApp, favorecendo maior participação da população nas campanhas eleitorais e no processo de construção da opinião pública.

\subsection{A construção da opinião pública no contexto digital}

A cada dia, a internet tem sido utilizada enquanto meio de comunicação política, principalmente em tempos de campanhas eleitorais, sejam no contexto nacional ou local. Satuf e Vasconcelos apontam que dentre as principais funções que a rede eletrônica pode desempenhar enquanto ferramenta de campanha, estão a disseminação de informações com enquadramento próprio, a distribuição de materiais de campanha, a mobilização de apoiadores e a participação dos cidadãos no processo eleitoral. (SATUF e VASCONCELOS, 2019)

Os autores supracitados acrescem que a popularidade da internet pode atrair mais pessoas para o processo democrático, especialmente os mais jovens. Por outra banda, Cardoso et al (2018), aponta que o consumidor digital tornou-se mais ativo, deixando de ser mero receptor e passando a ser transmissor e gerador de conteúdo, possuindo acesso às informações, conhecendo, questionando, comparando e divulgando sua opinião.

Interessa expor que a internet tem a capacidade de atingir vários e grandes públicos, com interesses individuais e coletivos e, por conta desse grande alcance, sua influência sobre os usuários é expressiva, considerando tanto o lado positivo quanto negativo.

Pereira (2017) registra que

a opinião pública é hoje manipulada pelo uso político dessas ferramentas digitais em associação com técnicas que combinam a garimpagem de grandes conjuntos de dados sobre indivíduos e a criação de contas de 
usuários robóticos, que inundam a rede de materiais panfletários, notícias falsas, campanhas de desinformação e críticas difamatórias, usando algoritmos programados (que aprendem artificialmente e medeiam debates). (...)

(...) O uso instrumental das redes sociais no Brasil tem sido orientado à fabricação artificial de consensos políticos nas redes sociais, disseminação de campanhas difamatórias, fabricação de falsas notícias e ações de desinformação. Esses recursos tem guiado a opinião pública, manipulando pesquisas virtuais, disputas narrativas e a percepção pública de temas determinantes para a democracia. (PEREIRA, 2017, p. 4)

Nesse contexto, interessa dizer que a utilização das redes sociais deve ser feita com um olhar crítico acerca daquilo que é posto como verdade, a fim de não manipular os usuários com informações falaciosas.

O uso da internet por parte dos brasileiros vem crescendo espantosamente, principalmente pela expansão do uso de smartphones, que acessam a internet de praticamente todos os lugares do planeta. No campo da política, uma atenção redobrada deve ser direcionada aquilo que é visto nas redes sociais.

Não é possível falar de acesso a internet sem se remeter a sua influência a opinião pública, já que no Brasil são mais de 134 milhões de usuários. Para Barros, Sauerbronn e Ayrosa (2012 apud COSTA, 2018), a principal característica do eleitor brasileiro não é sua identidade ideológica, mas a emoção. Assim, com a predominância de um eleitor mais emocional que racional, a comunicação e a mídia passam a ter um papel fundamental na decisão do voto, visto que o eleitor tende a estar muito mais preocupado com a imagem e os vínculos afetivos do que com as propostas de governo propriamente ditas. (COSTA, 2018, p. 61)

De acordo com o Tribunal Superior Eleitoral - TSE, em setembro de 2020 foram contabilizados 147.918 .483 cidadãos aptos para o voto nos 5.586 municípios brasileiros. Desse total, a maior parte é do sexo feminino (52,25\%), seguido do sexo masculino (47,68\%), com faixa etária predominante de 25 a 59 anos e com escolaridade entre 0 ensino fundamental incompleto e o ensino médio completo. (BRASIL, 2020) Para Costa (2018), as condições da população e as características 
histórico-culturais de um país influenciam diretamente na forma como os meios de comunicação são utilizados em campanhas e como chegam aos eleitores.

Ressalta-se que nas campanhas eleitorais, o principal produto é o próprio candidato, devendo o mesmo criar possibilidades de estreitamento e vínculos entre o eleitorado, com empatia e representatividade.

\subsection{As Fakenews}

A Fakenews é um termo em inglês utilizado para fazer referência a informações falsas, principalmente nas redes sociais. No caso da política, as fakenews utilizam-se das mídias sociais para subverter as eleições e enfraquecer a confiança dos eleitores, indo além de ações maliciosas de grupos ou indivíduos.

Ao que se sabe, o uso de práticas desonestas na internet para influenciar as pessoas acontece desde 0 ano de 2010 no Brasil. Vale, todavia, ressaltar que o que torna um conteúdo mentiroso, é o seu alcance dentro das redes sociais, ou seja, o quanto esse conteúdo circula no mundo virtual.

Com a rapidez da internet, as fakenews acabam por serem disseminadas com a crença de se tratarem de notícias verdadeiras, muitas das vezes compartilhadas por pessoas próximas através de grupos como os de WhatsApp.

O combate das fakenews não é tarefa fácil, já que os autores são de difícil identificação. Para Costa (2018), a maneira mais efetiva de diminuir os impactos é a divulgação de informações a qual se tem certeza sua veracidade, impactando sobremaneira na disseminação das notícias falsas. Padim, em reportagem à R7, registra que é difícil o controle sobre as fake news, tendo em vista a rapidez com que as notícias são propagadas. (PADIM, 2020)

Para tanto, o TSE lançou em 2020 uma campanha contra a divulgação de fake news. A "\#EuVotoSemfake" busca conscientizar os eleitores sobre o papel e a responsabilidade que eles tem na divulgação de informações durante as eleições 2020. (R7, 2020) Todavia, importa registrar é que a fake news deve ser monitorada, respondida e principalmente, denunciada. 


\section{A INFLUÊNCIA DAS MÍDIAS SOCIAIS PARA AS CAMPANHAS POLÍTICAS NO BRASIL}

\subsection{As eleições municipais de 2020}

O ano de 2020 seguiu como um dos mais desafiadores no campo da saúde dos últimos tempos, ao qual trouxe rebatimentos expressivos nas mais diversas áreas, como a economia e a educação. O contexto da Pandemia pela COVID-19, o isolamento social e o movimento de abre/fecha comércio foi uma constante no Brasil e na maior parte dos países do mundo. Em ano eleitoral, tal realidade impacta diretamente na forma de fazer política e nos resultados das urnas.

Conforme pesquisa realizada por Schreiber (2020) através do Instituto Internacional pela Democracia e Assistência Eleitoral (IDEA), das 41 (quarenta e uma) eleições realizadas em 2020 pelo mundo, 26 (vinte e seis) delas registraram um aumento na abstenção em comparação aos pleitos anteriores, em virtude da COVID-19. Tal realidade pode ser reproduzida nas eleições municipais brasileiras, previstas para o dia 15 de novembro de 2020.

Barros aponta que várias medidas entrarão em vigor para garantir a segurança sanitária nas eleições, tendo em via a pandemia, dentre elas, é possível destacar

mudanças nas datas, com a aprovação da PEC 18/2020; ausência da biometria; intensificação do marketing eleitoral por meio das mídias sociais (processo que era feito preferencialmente através da TV e do rádio); e inviabilidade das aglomerações nas convenções partidárias. (BARROS, 2020, p. 1)

Nesse contexto, o TSE tem realizado uma série de orientações sanitárias para os partidos e candidatos em 2020, tais como calcular o número de pessoas presentes de acordo com a capacidade local, promovendo distanciamento de um metro entre as pessoas e evitar a distribuição de materiais impressos. Outra medida que deve ser adotada é de não servir refeições nos espaços e que estes sejam abertos e amplos, a fim de evitar aglomerações. 
Por outra banda, atendo-se pela restrição do contato físico, os candidatos devem migrar suas campanhas para a internet. Frente ao exposto, a internet ganha força maior e o elemento digital apresenta-se agora como fundamental para o desenvolvimento das campanhas.

Assim como na campanha presencial, a Justiça Eleitoral estabeleceu normas para o funcionamento e divulgação de conteúdo político nas redes sociais. Um ponto importante é que a publicidade só é permitida se realizada pela conta oficial do candidato. Lives com candidatos e artistas ficou proibido. No que tange a boca de urna, o crime também é considerado quando feito através da internet. (TSE, 2020)

No contexto da pandemia pela COVID-19, a proliferação dos debates via YouTube,lives e postagens no feede stories do Instagram e Facebook dos candidados a prefeito municipais, multiplicaram-se e tais ferramentas tornam-se veículo forte de campanha. Os passos do candidato são registrados e postados com dedicação profissional, levando os instrumentais das mídias sociais a uma das principais ações de marketing político na atualidade.

O número de seguidores, de likese de visualizações apontam como um termômetro nas intenções de voto e aproximam o candidato do eleitorado, através da interação entre ambos nas livese da troca de mensagens no feedeno direct.

Ainda assim, mesmo com toda sua força, a internet não faz campanha política sozinha. Os candidatos devem se ater a uma série de ações via internet e fora dela, como instrumentos complementares e não menos importantes na corrida pela prefeitura.

\subsection{As mídias sociais como instrumento de fortalecimento das eleições 2020 no contexto brasileiro}

Certo se faz afirmar que as mídias sociais que as eleições 2020 no Brasil adentraram um contexto bastante atípico do acostumado nas eleições anteriores, tendo em vista o enfrentamento da pandemia pela COVID-19.

Centeno registra que 
esta é a primeira eleição em meio a uma pandemia, o que em si já impõe uma nova dinâmica. Ela impactará aspectos estruturais e imponderáveis como o nível de comparecimento nas seções de votação, bem como a dinâmica de campanha, com o aumento ainda maior do peso das redes sociais, bem como das mídias tradicionais, com as limitações para o corpo a corpo. (...)

(...) esta será a eleição com o maior número de candidatos da história, provavelmente estimulada pela necessidade dos partidos fortalecerem suas bancadas de vereadores, lançando candidatos majoritários. (CENTENO, 2020, p. 2)

Para Mendes, o poder depositado pelas mídias sociais nas mãos de cidadãos comuns reflete em potencial na área política, visto que passados a ter voz, os eleitores exigem cada vez mais políticos melhor preparados para expor suas propostas e opiniões. Para o autor, quem não acompanhar essas tecnologias, ficará para trás, ressaltando que a classe política está sem o devido preparo e conhecimento referente a força das redes sociais. (MENDES, 2020)

A respeito do uso das mídias sociais como instrumento de fortalecimento das eleições 2020, vale apontar que tal perspectiva apresenta-se em ascensão. Valente (2020) ressalta que em pesquisa divulgada pelo Instituto DataSenado, no ano de 2019, 45\% dos brasileiros afirmaram ter levado as redes sociais em conta para a decisão do voto e $80 \%$ dos participantes afirmaram ver grande influência na opinião pública.

Miras aponta que apesar do ainda mal uso das mídias sociais, os candidatos a prefeito nas eleições 2020 já contavam com esse recurso tecnológico em seus projetos de campanha. Este registra que a maioria dos candidatos entendem que 0 marketing político nas mídias sociais trata-se essencialmente de uma formatação digital do marketing político tradicional. (MIRAS, 2020)

Zeca Martins afirma que as redes sociais apresentam forte impacto no pleito eleitoral, principalmente em trabalhos a longo prazo, já que para ele, é importante que as redes sociais sejam putadas pela continuidade. $O$ autor registra que "ter um perfil em uma rede social não vai garantir a eleição de ninguém. As ações de 
marketing político digital devem ser planejadas e sincronizadas com outras ações da campanha, inclusive as do marketing convencional". (MARTINS, 2018 apud VALENTE, 2020, p. 4)

Para o fortalecimento das campanhas eleitorais, mais do que utilização de mídias sociais, os candidatos devem ser verdadeiros, apresentar postura ética e comprometimento com o eleitorado. Este deve atuar de forma que apresente um diagnóstico da realidade local e trazer propostas que se encaixem nas demandas e necessidades da população. Se por um lado as mídias sociais e as tecnologias ampliaram o leque de interação e contato com os eleitores, o mesmo tem direcionado a opinião pública a partir da capacidade técnica e qualidade das propostas, o que acaba por triar aqueles que tem condições de fazer um bom governo e os que não tem.

\section{Considerações Finais}

É certo afirmar que o marketing político está ligado a uma prática há anos desenvolvida por candidatos a eleições em todo o mundo. Todavia, a prática do marketing político digital adentra a agenda nacional apenas nos anos 90, e ganha força a partir de 2010, após a bem sucedida campanha do ex-presidente norteamericano Barack Obama.

De lá para cá, o uso da tecnologia e o alcance de expressivo de informações a partir das mídias sociais trouxe a realidade um forte instrumento para os candidatos no processo de campanha eleitoral. Isso se dá em virtude da popularização da internet, do acesso não apenas aos computadores, mas especialmente aos smartphones, a banda larga e aos 4G.

Mais do que um instrumento de campanha e marketing político, as mídias sociais contribuíram para a dicotomia entre prática eleitoral dos candidatos pela via das campanhas políticas e para a construção de um eleitorado mais crítico, questionador, exigente e participante. Nesse contexto, as redes sociais servem como uma espécie de termômetro, ao qual se pode verificar o quão o candidato está tendo aceitação ou rejeição do público.

Vale pontuar que o uso do marketing político digital vai muito mais que uma 
tendência mundial, é a nova forma de interação entre as pessoas, todavia, não se trata, nem deve ser tratado como única fonte de campanha política, caracterizando-se com fundamental, mas que deve se dar atrelado às formas convencionais de marketing político.

\section{Referências}

BARROS, T.C.A. et al.A pandemia como estratégia política nas eleições 2020. 2020. Disponível em: <https://www.observatoriodasmetropoles.net.br/a-pandemiacomo-estrategia-politica-nas-eleicoes-2020/>. Acesso em 04 de novembro 2020.

BELMONTE, A. Palanque digital poderá decidir eleições de 2018. Jornal VS. 2018. Disponível em:

<https://www.jornalvs.com.br/_conteudo/2018/03/noticias/regiao/2244030palanque-digital-podera-decidir-eleicoes-de-2018.html>. Acesso em 28 de outubro 2020.

BRAGA, S.; CARLOMAGNO, M. Eleições como de costume? Uma análise longitudinal das mudanças provocadas nas campanhas eleitorais brasileiras pelas tecnologias digitais (1998-2016). 2018. Disponível em:

<https://www.scielo.br/pdf/rbcpol/n26/2178-4884-rbcpol-26-

7.pdfhttps://www.scielo.br/pdf/rbcpol/n26/2178-4884-rbcpol-26-7.pdf>. Acesso em 30 de outubro 2020.

BRASIL. Lei no 12.034 de 29 de setembro de 2009. Altera as Leis no 9.096 de 19 de setembro de 1995 - Lei dos Partidos Políticos, Lei o 9.504 de 30 de setembro de 1997, que estabelece normas para as eleições e, 4.737 de 15 de julho de 1965 - Código Eleitoral. Disponível em: <http://www.planalto.gov.br/ccivil_03/_ato20072010/2009/lei/12034.htm>. Acesso em 27 de outubro 2020.

BRASIL. Lei no $\mathbf{1 2 . 9 6 5}$ de $\mathbf{2 3}$ de abril de 2014. Estabelece princípios, garantias, direitos e deveres para o uso da internet no Brasil. 2014. Disponível em: <http://www.planalto.gov.br/ccivil_03/_ato2011-2014/2014/lei//12965.htm>. Acesso em 30 de outubro 2020. 
BRASIL. TSE. Estatísticas do Eleitorado 2020. Disponível em:

$<$ https://www.tse.jus.br/eleitor/estatisticas-de-eleitorado/estatistica-do-eleitoradopor-sexo-e-faixa-etaria>. Acesso em 01 de novembro 2020.

CARDOSO, M. et al. Política Digital: as mídias digitais como palanque na eleição municipal de Blumenau/SC. 2018. Disponível em:

<file:///C:/Users/joao/Downloads/26014-172686-1-PB.pdf>. Acesso em 26 de outubro 2020.

CENTENO, L. Eleições 2020: o que é possível projetar como cenário para 2022? 2020. Disponível em: <https://www.brasildefato.com.br/2020/10/22/artigo-eleicoes2020-o-que-e-possivel-projetar-como-cenario-para-2022>. Acesso em 30 de outubro 2020.

COSTA, J.C. Redes Sociais e Eleições: o uso das novas mídias em campanhas eleitorais brasileiras. Rio de Janeiro, 2018. (monografia). Disponível em: https://pantheon.ufrj.br/bitstream/11422/8605/1/JCosta.pdf>. Acesso em 26 de outubro 2020.

CRUZ, F.B. (org). Internet e Eleições no Brasil. 2019/2020. Disponível em: $<$ https://www.internetlab.org.br/wp-content/uploads/2019/09/policy-infopol26919_4.pdf>. Acesso em 28 de outubro 2020.

GAMA, F. Política na rede: o uso das redes sociais nas eleições municipais de Salvador. 2013. Disponível em: <http://gitsufba.net/anais/wpcontent/uploads/2013/09/13n3_politica_49513.pdf>. Acesso em 28 de outubro 2020.

\section{GROSSELLI, G. Marketing Político Digital - as novas tecnologias de} comunicação e as campanhas eleitorais. 2010. Disponível em:

<file:///C:/Users/servs/Downloads/44-Texto\%20do\%20artigo-289-1-1020101101\%20(1).pdf>. Acesso em 26 de outubro 2020.

MENDES, C. Mais do que nunca, 2020 será uma campanha das mídias sociais. 2020. Disponível em: <https://j|politica.com.br/entrevista/cicero-mendes-mais-doque-nunca-2020-sera-uma-campanha-das-midias-sociais>. Acesso em 04 de novembro 2020. 
MIRAS, J. Candidatos não usam bem as redes sociais. 2020. Disponível em: <https://blogdarose.band.uol.com.br/artigo-candidatos-nao-usam-bem-as-redessociais/>. Acesso em 05 de novembro 2020.

MOLINA, J.R. Marketing Político Digital: como engajar eleitores nas ideias de um candidato. In:Revista Interdisciplinar de Ciência Aplicada. 2019. Disponível em: $<$ http://ucs.br/etc/revistas/index.php/ricaucs/article/view/7480>. Acesso em 18 de outubro 2020.

\section{NIEWEGLOWSKI, M.C.B. Marketing Político e as estratégias de comunicação} que influenciam na decisão de voto do eleitor nas mais variadas esferas da sociedade atual. UFPA, 2013. Disponível em:

<https://acervodigital.ufpr.br/bitstream/handle/1884/46746/MARIANA\%20CABECAS \%20BASSFELD\%20NIEWEGLOWSKI.pdf? sequence=1\&isAllowed $=y>$. Acesso em 27 de outubro 2020.

OLIVEIRA, M.V.S. Mudanças nas estratégias do marketing político na era da comunicação em rede: a relação entre a cultura digital, as novas formas interativas e a constituição das estratégias de marketing político digital. 2015.

Disponível em: <https://www.fapcom.edu.br/revista/index.php/revistacomfilotec/article/view/171 >. Acesso em 23 de outubro 2020.

PENTEADO, C.L.C. Marketing político na era digital: perspectivas e possibilidades. In: Revista USP. 2011. Disponível em:

<https://www.researchgate.net/publication/274357948_MARKETING_POLITICO_N A_ERA_DIGITAL_PERSPECTIVAS_E_POSSIBILIDADES>. Acesso em 15 outubro 2020.

PEREIRA, B.A. Manipulando virtualmente a opinião pública. 2017. Disponível em: <https://www.infomoney.com.br/colunistas/pensando-politica/manipulandovirtualmente-a-opiniao-publica/>. Acesso em 29 de outubro 2020.

PIMENTA, J.A.; FERREIRA, M.A. Marketing: Marketing Político Digital. 2017.

SATUF, I.; VASCONCELOS, W.G.I. As Estratégias Políticas na História: uma análise das influências das mídias televisiva e digital nas campanhas presidenciais de 2002 e 2018. Alcar. Natal, 2019. 